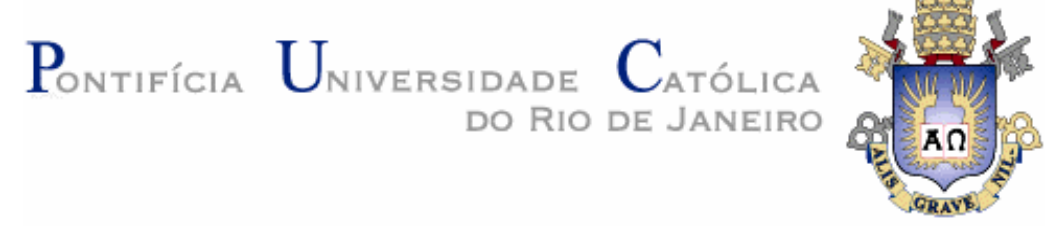

José Eduardo Vasconcellos Amarante

\title{
ANÁLISE DA DISTRIBUIÇÃO DE TENSÕES EM DIFERENTES TERMINAÇÕES CERVICAIS DE COROAS UNITÁRIAS TOTALMENTE CERÂMICAS
}

Dissertação de Mestrado

Dissertação apresentada como requisito parcial para a obtenção do grau de Mestre em Ciências da Engenharia Metalúrgica pelo Programa de PósGraduação em Engenharia Metalúrgica do Departamento de Ciências dos Materiais e Metalurgia da PUC-Rio.

Orientador: Marcos Venicius Soares Pereira

Co- Orientador: Adalberto Bastos de Vasconcellos 


\section{ANÁLISE DA DISTRIBUIÇÃO DE TENSÕES EM DIFERENTES TERMINAÇÕES CERVICAIS DE COROAS UNITÁRIAS TOTALMENTE CERÂMICAS}

Dissertação apresentada como requisito parcial para a obtenção do grau de Mestre em Ciências da Engenharia Metalúrgica pelo Programa de PósGraduação em Engenharia Metalúrgica do Departamento de Ciências dos Materiais e Metalurgia da PUC-Rio.

Prof. Marcos Venicius Soares Pereira Orientador Departamento de Ciência dos Materiais e Metalurgia PUC-Rio

Dr. Adalberto Bastos de Vasconcellos Co-Orientador Departamento de Odontotécnica

Prof. Cláudio Pinheiro Fernandes Universidade Veiga de Almeida

Prof. Arnaldo Freitas Camarão ArvinMeritor / São Paulo

Prof. Ney Augusto Dumont Coordenador Setorial de Pós-Graduação do Centro Técnico Cientifico da PUC-Rio

Rio de Janeiro, 05 de dezembro de 2003 
Todos os direitos reservados. É proibida a reprodução total ou parcial do trabalho sem autorização da universidade, do autor e do orientador.

\section{José Eduardo Vasconcellos Amarante}

Graduou-se em Odontologia pela Faculdade de Odontologia de Nova Friburgo em 1992. Especialista em Docência Superior pela UNIGRANRIO. Defendeu dissertação de mestrado em Clínica Odontológica na UFF em abril de 2001. Foi professor do Curso de Especialização em Prótese Dentária da UFF. Atual coordenador de Clínica Integrada II, professor de Prótese Dentária e Escultura Dentária da UNIVERSO e professor de Prótese Dentária da USS.

Ficha Catalográfica

Amarante, José Eduardo Vasconcellos

Análise da distribuição de tensões em diferentes terminações cervicais de coroas unitárias totalmente cerâmicas / José Eduardo Vasconcellos Amarante; orientador: Marcos Venicius Soares Pereira ; co-orientador: Adalberto Bastos de Vasconcellos. Rio de Janeiro : PUC-Rio, 2003.

102 f. : il. ; $30 \mathrm{~cm}$

Dissertação (mestrado) - Pontifícia Universidade Católica do Rio de Janeiro, Departamento de Ciências dos Materiais e Metalurgia.

Inclui referências bibliográficas

1. Ciência dos materiais e metalurgia - Teses. 2. Biomateriais. 3. Odontologia. 4. Bioengenharia. 5. Terminação cervical. I. Pereira, Marcos Venicius Soares. II. Vasconcellos, Adalberto Bastos. III. Pontifícia Universidade Católica do Rio de Janeiro. Departamento de Ciência dos Materiais e Metaluraia. IV. Título. 


\section{Agradecimentos}

Ao Prof. Marcos Venicius Soares Pereira por sua orientação na realização desta pesquisa.

Ao Dr. Arnaldo Freitas Camarão pelo incentivo e apoio que sempre me deu e por sua participação fundamental neste trabalho.

Ao Prof. Orlando Chevitarese in memorian que foi o responsável pelo meu encaminhamento à este mestrado e pela grande admiração que mantenho por ele.

Ao Prof. Adalberto Bastos de Vasconcellos por sua amizade e pelos conhecimentos técnicos aplicados neste trabalho.

A Martha Vasconcellos Amarante por sua inestimável contribuição.

A Arvinmeritor - São Paulo que possibilitou a realização das simulações.

Aos funcionários do DCMM pelo carinho e atenção dispensados a mim.

Aos alunos e professores do mestrado.

A todos que, de certa forma, contribuíram para a realização deste trabalho.

E principalmente a minha família. 


\section{Resumo}

Amarante, José Eduardo Vasconcellos; Pereira, Marcos Venicius Soares (Orientador). Análise da distribuição de tensões em diferentes terminações cervicais de coroas unitárias totalmente cerâmicas. Rio de Janeiro, 2003. 124p. Dissertação de Mestrado - Departamento de Ciência dos Materiais e Metalurgia, Pontifícia Universidade Católica do Rio de Janeiro.

Este estudo apresenta uma análise numérica pelo método de elementos finitos da distribuição de tensões em dentes restaurados com coroas unitárias totalmente cerâmicas de diferentes tipos de terminações cervicais.

Para a obtenção do modelo numérico bi-dimensional, três modelos da região de molares inferiores foram criados a partir de uma peça anatômica real e simularam a aplicação de coroas cerâmicas puras com diferentes terminações cervicais no segundo molar. O material selecionado para as restaurações foi uma cerâmica reforçada por dissilicato de lítio, enquanto que as terminações cervicais adotadas foram do tipo ombro reto, ombro arredondado e chanfro. Com o objetivo de realizar uma análise mais criteriosa das distribuições de tensões inerentes aos diferentes tipos de terminações cervicais, optou-se por criar o mesmo modelo em uma condição totalmente hígida, isto é, com ausência de qualquer tipo de restauração. A simulação numérica foi realizada pelo software ANSYS 7.0, sendo os modelos carregados com uma força estática de $400 \mathrm{~N}$ distribuída uniformemente na espessura dos dentes e subdividida em pontos de aplicação nas superfícies oclusais dos elementos dentais de acordo com a relação cúspide-crista. Os vetores correspondentes à aplicação das forças foram direcionados para região ânteroinferior da mandíbula com uma angulação de $15^{\circ}$.

Os resultados mostraram que a restauração envolvendo a coroa cerâmica com terminação cervical em ombro reto concentrou mais tensões no dente molar restaurado, seguida pela coroa cerâmica com uma terminação cervical do tipo ombro arredondado. Por sua vez, a coroa cerâmica com a terminação cervical em chanfro provocou uma distribuição de tensões mais homogênea no dente molar restaurado.

\section{Palavras-chave}

Odontologia; terminação cervical; biomateriais; bioengenharia; método de elementos finitos. 


\section{Abstract}

Amarante, José Eduardo Vasconcellos; Pereira, Marcos Venicius Soares (Advisor). Analysis of stress distribution in different finishing lines of single all-ceramic crowns. Rio de Janeiro, 2003. 124p. M.Sc. Dissertation - Departamento de Ciência dos Materiais e Metalurgia, Pontifícia Universidade Católica do Rio de Janeiro.

This work presents a finite element analysis of the stress distribution in teeth restored by single all-ceramic crowns with different types of finishing lines.

In order to obtain the 2-D numerical model, three models of the mandibular molar teeth region were created considering a real anatomic piece and were then used to simulate the application of all-ceramic crowns with different finishing lines on the second molar. The selected material for the restorations was a ceramic material reinforced by lithium disilicate and the finishing lines adopted were shoulder, rounded shoulder and chamfer type. Aiming to realize a more careful analysis of the stress distributions associated with the different finishing lines, the same model was created in a completely healthy condition, i. e., in the absence of any kind of restoration. The numerical simulation was carried out by the ANSYS 7.0 software loading the models with $400 \mathrm{~N}$ distributed by the teeth' thickness and applied according to the cusp-crest relationship at points in the teeth' oclusal surfaces. The vectors corresponding to the applied forces were oriented towards the former-inferior mandibular region at the angle of $15^{\circ}$.

The results indicated that the restoration involving the all-ceramic crown with the shoulder type finishing line intensified the stress in the restored molar tooth, followed by the all-ceramic crown with the rounded shoulder. On the other hand, the all-ceramic crown with the chamfer type finishing line caused a more homogeneous stress distribution in the restored molar tooth.

\section{Keywords}

Dentistry; finishing lines; biomaterials; bioengineering; finite element method. 


\section{Sumário}

1 Introdução

2 Revisão da Literatura

15

2.1. Histórico das cerâmicas odontológicas

15

2.2. Cerâmicas odontológicas: propriedades e análise de tensões 16

2.3. Princípios de preparos e cimentação para coroas totalmente cerâmicas

2.3.1. Preservação da estrutura dentária 21

2.3.2. Retenção 22

2.3.3. Estabilidade estrutural 23

2.3.4. Integridade das margens do preparo 24

2.3.5. Cimentação da restauração 24

2.4. Configurações de terminações cervicais em preparos dentários para coroas totalmente cerâmicas. 26

2.4.1. Terminação cervical em ombro ou degrau 26

2.4.2. Terminação cervical em ombro arredondado $\quad 27$

2.4.3. Terminação cervical em chanfro 28

2.5. Método de elementos finitos 29

3 Materiais e Métodos $\quad 37$

3.1. Obtenção dos modelos $\quad 37$

3.2. Aplicação da malha e condições de contorno 42

3.3. Processamento pelo método dos elementos finitos 53

4 Apresentação dos Resultados

4.1. Deflexões 56

4.2. Distribuição das tensões de cisalhamento no plano $X-Y \quad 57$

4.2.1. Modelo com a terminação cervical em ombro reto 57

4.2.2. Modelo com a terminação cervical em ombro arredondado $\quad 59$

4.2.3. Modelo com a terminação cervical em chanfro 61

4.2.4. Modelo com os dentes hígidos 63

4.3. Distribuição das tensões principais 65

4.3.1. Modelo com a terminação cervical em ombro reto 65

4.3.2. Modelo com a terminação cervical em ombro arredondado 67

4.3.3. Modelo com a terminação cervical em chanfro 69

4.3.4. Modelo com os dentes hígidos $\quad 71$

4.4. Distribuição das tensões equivalentes de von Mises 73

4.4.1. Modelo com a terminação cervical em ombro reto 73

4.4.2. Modelo com a terminação cervical em ombro arredondado 74

4.4.3. Modelo com a terminação cervical em chanfro 76

4.4.4. Modelo com os dentes hígidos 78

4.5. Distribuição das tensões com coeficiente de atrito nas áreas de contato. $\quad 80$

4.5.1. Distribuição das tensões cisalhantes. 81

4.5.2. Distribuição das tensões principais. 82

4.5.3. Distribuição das tensões equivalentes de von Mises. 84 
5 Discussão dos Resultados

87

5.1. Tensões de cisalhamento $\quad 87$

5.2. Tensões principais $\quad 89$

5.3. Tensões de von Mises 91

6 Conclusões 94

7 REFERÊNCIAS BIBLIOGRÁFICAS 96 


\section{Lista de figuras}

Figura 1 - Terminação cervical em ombro. 27

Figura 2 - Terminação cervical em chanfro. 28

Figura 3 - Modelo a ser processado. 30

Figura 4 - Colocação da malha. $\quad 31$

Figura 5 - Visualização dos nós. 32

Figura 6 - Imposição das condições de contorno. 33

Figura 7 - Representação gráfica das tensões. 34

Figura 8 - Imagem raster da peça anatômica adotada para a geração dos

modelos bi-dimensionais 38

Figura 9 - Imagem vector da peça anatômica. $\quad 39$

Figura 10 - Coroa com terminação cervical em ombro reto. 41

Figura 11 - Coroa com terminação em ombro arredondado. 41

Figura 12 - Coroa com terminação em chanfro. 42

Figura 13 - Aplicação da malha no modelo com uma restauração no

segundo molar de cerâmica pura e término cervical em ombro reto. 43

Figura 14 - Aplicação da malha no modelo com uma restauração no

segundo molar de cerâmica pura e o término cervical em ombro arredondado.

Figura 15 - Aplicação da malha no modelo com uma restauração no segundo molar de cerâmica pura e o término cervical em chanfro.

Figura 16 - Aplicação da malha no modelo com todos os dentes hígidos.

Figura 17 - Detalhamento dos elementos mostrando a continuidade da malha nas diferentes regiões do modelo.

Figura 18 - Esquema demonstrando a colocação das molas em função da estrutura anatômica.

Figura 19 - Visualização das condições de contorno aplicadas no modelo restaurado com terminação cervical em ombro reto: restrições na borda óssea inferior e posterior, molas na borda óssea anterior e na área de contato mesial do primeiro molar e carregamentos nas superfícies oclusais dos dentes.

Figura 20 - Visualização das condições de contorno aplicadas no modelo restaurado com terminação cervical em ombro arredondado: restrições na borda óssea inferior e posterior, molas na borda óssea anterior e na área de contato mesial do primeiro molar e carregamentos nas superfícies oclusais dos dentes.

Figura 21 - Visualização das condições de contorno aplicadas no modelo restaurado com terminação cervical em chanfro: restrições na borda óssea inferior e posterior, molas na borda óssea anterior e na área de contato mesial do primeiro molar e carregamentos nas superfícies oclusais dos dentes.

Figura 22 - Visualização das condições de contorno aplicadas no modelo com todos os dentes hígidos: restrições na borda óssea inferior e posterior, molas na borda óssea anterior e na área de contato mesial do primeiro molar e carregamentos nas superfícies oclusais dos dentes. 53 Figura 23 - Exemplificação das deflexões do modelo com dentes hígidos. 
Figura 24 - Distribuição das tensões de cisalhamento no modelo após restauração com coroa de cerâmica e terminação cervical em ombro reto.

Figura 25 - Detalhamento da figura anterior na região de segundo molar.

Figura 26 - Distribuição das tensões de cisalhamento no modelo após restauração com coroa de cerâmica e terminação cervical em ombro arredondado.

Figura 27 - Detalhamento da figura anterior na região de segundo molar.

Figura 28 - Distribuição das tensões de cisalhamento no modelo restaurado com coroa de cerâmica e terminação cervical em chanfro.

Figura 29 - Detalhamento da figura anterior na região de segundo molar.

Figura 30 - Distribuição das tensões de cisalhamento no modelo com dentes hígidos.

Figura 31 - Detalhamento da figura anterior na região do segundo molar.

Figura 32 - Distribuição das tensões principais no modelo restaurado com coroa de cerâmica e terminação cervical em ombro reto.

Figura 33 - Distribuição das tensões principais na região cervical do modelo apresentado na figura anterior.

Figura 34 - Distribuição das tensões principais no modelo restaurado com coroa de cerâmica e terminação cervical em ombro arredondado. $\quad 68$ Figura 35 - Distribuição das tensões principais na região cervical do modelo apresentado na Figura 34.

Figura 36 - Distribuição das tensões principais no modelo restaurado com cerâmica e terminação cervical em chanfro.

Figura 37 - Distribuição das tensões principais na região cervical do modelo apresentado na figura anterior.

Figura 38 - Distribuição das tensões principais no modelo com os dentes hígidos.

Figura 39 - Detalhamento da figura anterior na região de segundo molar.

Figura 40 - Distribuição das tensões de von Mises no modelo restaurado com coroa de cerâmica e terminação cervical em ombro reto.

Figura 41 - Detalhamento da distribuição das tensões de von Mises apresentada na figura anterior.

Figura 42 - Distribuição das tensões de von Mises no modelo restaurado com coroa de cerâmica e terminação cervical em ombro arredondado. 75 Figura 43 - Detalhe da distribuição das tensões de von Mises no mesmo modelo.

Figura 44 - Distribuição das tensões de von Mises no modelo restaurado com coroa de cerâmica e terminação cervical em chanfro.

Figura 45 - Detalhamento da distribuição das tensões de von Mises na região do segundo molar.

Figura 46 - Distribuição das tensões de von Mises no modelo com dentes hígidos

Figura 47 - Distribuição das tensões de von Mises na região cervical do mesmo modelo.

Figura 48 - Distribuição das tensões de cisalhantes no modelo restaurado com coroa de cerâmica e terminação cervical em ombro reto e com coeficiente de atrito nas áreas de contato. 
Figura 49 - Distribuição das tensões de cisalhamento na região cervical do mesmo modelo.

Figura 50 - Distribuição das tensões principais no modelo restaurado com coroa de cerâmica e terminação cervical em ombro reto e com coeficiente de atrito nas áreas de contato.

Figura 51 - Distribuição das tensões de cisalhamento na região cervical do mesmo modelo.

Figura 52 - Distribuição das tensões de von Mises no modelo restaurado com coroa de cerâmica e terminação cervical em ombro reto e com coeficiente de atrito nas áreas de contato.

Figura 53 - Detalhamento da figura anterior na região de segundo molar. 


\section{Lista de tabelas}

Tabela 1 - Propriedades elásticas dos materiais adotados na simulação numérica Tabela 2 - Deflexões máximas sofridas pelos modelos restaurados e de dentes hígidos. 